\title{
Comparing public policy implementation in Taiwan and Vietnam in the early stages of the COVID-19 outbreak: a review
}

Matias Acosta - Argentine Accelerator Lab, United Nations Development Programme, 130 Esmeralda St, C1035ABD Ciudad Autónoma de Buenos Aires, Argentina

Matias Nestore - Culture, Politics and Global Justice Research Cluster, Faculty of Education, University of Cambridge, 184 Hills Road, Cambridge, CB28PQ, United Kingdom

Keywords: COVID-19, public policy, Taiwan, Vietnam.

Taiwan and Vietnam have taken successful measures to combat the spread of COVID-19 at the early stages. Many authors attributed the successful policies to the lessons learned by these countries during the severe acute respiratory syndrome (SARS) pandemic in 2002.(Ohara, 2004) This manuscript provides a summary of recent early-stage policies that were successful in mitigating the spread and creating resilience against the negative consequences of COVID-19 in Taiwan and Vietnam. Crucially, these policies go beyond and complement social isolation. As social isolation is expected to have a negative socio-economic impact on the population and adherence is likely to decrease with time(Armitage and Nellums, 2020; Weems et al., 2020), it is important to consider a broad range of policies to promote a steady control of the COVID-19 spread. Initially, we provide a brief introduction to some general concepts related to COVID-19. Thereafter, we introduce a concise review of policies and their dates relative to the first detection case in Taiwan and Vietnam as well as doing a comparative analysis.

\section{Background}

Taiwan and Vietnam have been quite effective in the early development of strategies to mitigate the spread and impact of COVID-19. These measures included initiating specific policy protocols, interministerial coordination, strategies of information management, specific financial decisions, measures to prevent and control infection in hospitals, as well as increasing laboratory testing capacity in private, public, and university laboratories.(Legido-Quigley et al., 2020)

The COVID-19 epidemic curves can be adequately described by conventional models from physics and epidemiology.(Bastos and Cajueiro, 2020; Squillante et al., 2020) However, the course of an epidemic is determined by many factors, many of which are not yet understood. An important parameter that defines the mean number of secondary cases generated by one primary case is the basic reproduction number. If this number is larger than unity, it implies that an epidemic will occur. In China, initial estimates suggest a reproduction number around 2.5 for COVID-19. This implies that in the worst-case scenario up to around $60 \%$ of the population of the country could become infected.(Legido-Quigley et al., 2020)

Seasons may influence the reproduction number of COVID-19 but this is still unknown. This implies that, contrary to Influenza A, the epidemic may not cease even in summer.(Anderson et al., 2020) The case fatality rate is also unknown 
although, as of now, statistics show a preponderance of deaths in the elderly population. Another unknown element is whether infectiousness starts before the onset of symptoms, though some studies pinpoint the possibility that viremia might be high enough to trigger transmission 1 or 2 days before the onset of symptoms.(Zou et al., 2020) Moreover, the number of asymptomatic cases is unknown too, with some estimates suggesting that about $80 \%$ of people have mild or asymptomatic infections. The duration of the infectious period is also uncertain and the available virological data suggests that it lasts for 10 days or more after the incubation period.(Anderson et al., 2020; Zou et al., 2020)

Despite all the uncertain aspects related to COVID-19, both Taiwan and Vietnam have succeeded in mitigating the spread of COVID-19 and have also put in place strategies to promote resilience in their citizens against the crisis. Hence, we summarize what we consider some of the most important early-stage successful policies in both countries below.

\section{The case of Taiwan}

Taiwan was expected to have a large number of COVID-19 cases owing to its geographical proximity, high trade volume, and large exchange of people with China. (Wang et al., 2020) However, as of 04/07/2020 Taiwan only had 376 confirmed cases. (Webpage A)

The National Health Command Center (NHCC) played a key role in the rapid and coordinated response against COVID-19 in the country. NHCC acts as a unified central command system that includes the Central Epidemic Command Center (CDC), the Biological Pathogen Disaster Command Center, the CounterBioterrorism Command Center, and the Central Medical Emergency Operations Center.(Wang et al., 2020) Another important aspect was that soon after the first cases were detected, the government actively sought patients with respiratory symptoms, as well as providing a toll-free national and regional number to report suspicious symptoms or cases. The first case of COVID-19 in Taiwan was reported on January $21^{\text {st }}$, yet on the $20^{\text {th }}$ the CDC was already officially activated to begin working under NHCC. Besides, on January $21^{\text {st }}$ several coordinated efforts by various ministries began, including the ministries of transportation, economics, labor, and education. Moreover, the National Health Insurance Administration (NHIA) and the National Immigration Agency integrated patients' past 14-day travel history with their National Health Insurance identification card data in just one day. Taiwanese citizens' household registration, foreigners' entry cards, and mobile phone tracking systems were also important in tracking possible infected cases and planning quarantine measures. Yet, it is worth highlighting that tracking systems on a virus with a transmission number of 2.5 can be quite challenging.(Keeling et al., 2020) Moreover, contact tracing or any other symptom-based control system is unlikely to be sufficient owing to a large number of mild or asymptotic cases.(Anderson et al., 2020) Importantly, the Taiwanese government also re-allocated financial resources and reached citizens promptly to inform them about the situation.(Wang et al., 2020)

\section{The case of Vietnam}

Vietnam shares a border of 1,281 kilometers and has a high volume of trade with China. Moreover, it is under-resourced compared to Taiwan and China, and was, therefore, expected to have a high risk of transmission and mortality. 
The first case of COVID-19 in Vietnam was detected on January $23^{\text {rd }}$.(La et al., 2020) By February $13^{\text {th }}$, there were 16 cases reported, with the last recovery on February $25^{\text {th }}$. Between January $23^{\text {rd }}$ and February $25^{\text {th }}$ the increase in the number of confirmed cases in Vietnam was comparable to other countries like the United States and the United Kingdom. Nonetheless, no further cases were reported between February $13^{\text {th }}$ and March $5^{\text {th }}$ despite the large increase of infected people in many other countries worldwide. On March $6^{\text {th }}$, however, the $17^{\text {th }}$ case was detected which was attributed to individuals returning from overseas. As of March $22^{\text {nd }}$, the number of COVID-19 infections in Vietnam raised to 113 and as of 07/04/2020, Vietnam has a total of 249 reported cases. Thus, there have been two separate outbreaks of the disease in Vietnam; the first between January $23^{\text {rd }}$ and February $13^{\text {th }}$ (patients 1 to 16) and the second from March $6^{\text {th }}$ to date, 07/04/2020 (patients 17 to 249). An analysis between the first and second outbreaks is quite important to showcase the control measures of the government and also shed light that preliminary controls may not be sufficient but rather constant efforts are required.(Webpage B; La et al., 2020)

Vietnam has been relatively successful in containing COVID-19 spread, similarly as it had been during the SARS epidemic in 2002. The control of the SARS epidemic was attributed to the complete isolation of patients and the implementation of control measures from an early stage of the epidemic. (Ohara, 2004) In the case of the on-going COVID-19 outbreak other practices have also been elaborated, some of which are highlighted here.

As with the case of Taiwan, a highly rapid response was put in place. As of January $3^{\text {rd }}$, there was a tightening of the Vietnam-China border. Moreover, on January $10^{\text {th }}$ the Public Health Emergency Operation Center activated emergency measures. From this moment onwards, the Ministry of Health $(\mathrm{MoH})$, together with a purposely created national steering committee, coordinated governmental and civil society efforts with a particular focus on detection and prevention of spread. This was a similar strategy to that of the government of Taiwan implemented through the NHCC. Other important organizational aspects included the adjustment of prices of medical goods and equipment. Compliance with policies has been strictly and continuously monitored. Those organizations that did not comply with government policies received elevated fines.

As COVID-19 evolved, both central and local governments continually amended and created new policies. To transmit these rapid changes, the government developed tailored web pages and mobile applications for citizens in Vietnam and citizens abroad. An example of a very rapid response worth highlighting is the following: after the first case of domestic transmission, the government introduced a set of measures to prevent the virus from spreading, which included strategies of quarantine and isolation on suspected virus carriers and in specific geographical regions. Generally speaking, targeted social distancing and/or isolation has been suggested as an important strategy to mitigate several aspects related to COVID19 such as spread and mortality. (Anderson et al., 2020) Importantly, all government measures have been followed up with the provision of up-to-date information for citizens, training, and simulations to anticipate outbreaks. The official information was also produced in English to inform foreigners and expatriates in Vietnam. Strict measures to prevent fake news have also been promoted.(La et al., 2020) 


\section{Comparative analysis}

Table 1 shows a summary of the policy measures taken in Taiwan and Vietnam. All information was taken from the tables presented in the supplementary material. The steps before the detection of the first case involved assessing the risks, organizing coordinated multi-actor responses, and informing the public about the potential risks of the crisis. After the first case was detected, both countries implemented effective systems of coordinated action across ministries, emergency centers, and relevant industries. Moreover, the price of essential medical and sanitary equipment was fixed both in Taiwan and Vietnam, and schools closed or suspended by the 15th day after the first case was detected.

Despite acting similarly in the early stages of the epidemic, their strategies started differing as COVID-19 spread and interventions were carried out. This was expected, especially taking into consideration the different geographical, demographic, and economic characteristics of each country. Taiwan focused largely on restricting travel to/from the country and producing medical and sanitary equipment to prevent the spread of the virus internally. On the other hand, Vietnam's main focus was on the organization of healthcare provision, training of medical staff, and the limitation of activity in public spaces.

Table 1: Comparative analysis of public policies implemented in Taiwan and Vietnam. The information for the table was adapted from references (La et al., 2020; Wang et al., 2020). The summary of policies is presented and analyzed relative to the day of the first case detected in each country.

\begin{tabular}{|c|c|}
\hline Day & Summary of policies \\
\hline-74 & $\begin{array}{l}\text { Both countries start to implement the first interventions to prevent } \\
\text { the spread of infectious diseases. Operation centers in both countries } \\
\text { are activated to assess the situation and monitor passengers arriving } \\
\text { from infected regions. } \\
\text { Vietnam tightens quarantine at the border with China. } \\
\text { Taiwan inspects passengers for symptoms on flights from Wuhan. }\end{array}$ \\
\hline-7 & $\begin{array}{l}\text { Vietnam's Minister of Health issues guidelines for diagnosis and } \\
\text { treatment of COVID-19. } \\
\text { All suspected cases in Taiwan arriving from China are screened for } 26 \\
\text { different viruses }\end{array}$ \\
\hline 0 & $\begin{array}{l}\text { First COVID-19 case detected in Taiwan (21/01/2020) and Vietnam } \\
(23 / 01 / 2020)\end{array}$ \\
\hline 5 & $\begin{array}{l}\text { Coordination and action take place across ministries. In both } \\
\text { countries, ministries of Health, Education, Labour, and Foreign Affairs } \\
\text { start devising measures and taking actions. }\end{array}$ \\
\hline
\end{tabular}




\begin{tabular}{|c|c|}
\hline & $\begin{array}{l}\text { Vietnam: } \\
\text { - Center for Emergency Prevention and Control is activated. } \\
\text { Taiwan: } \\
\text { - Ministry of Health and Welfare promotes quarantine efforts } \\
\quad \text { through travel agents and tour guides. }\end{array}$ \\
\hline 10 & $\begin{array}{l}\text { Prevention and control measures are tightened in both countries. } \\
\text { Mask prices are fixed by government officials in both countries. } \\
\text { Vietnam: } \\
\text { - provinces start the provision of masks for high school students. } \\
\text { - passengers who were suspected of being infected are to be kept in } \\
\text { isolation. } \\
\text { - mass-media campaign on prevention and control of infection. } \\
\text { Taiwan: } \\
\text { - quarantined individuals are monitored through government-issued } \\
\text { cell phones } \\
\text { - production of masks rises to } 4 \text { million per day. }\end{array}$ \\
\hline 15 & $\begin{array}{l}\text { Both countries suspend/cancel school classes. } \\
\text { Vietnam: } \\
\text { - disinfection takes place in offices, hospitals, docks, bus stations, and } \\
\text { schools. } \\
\text { - cities start restricting activities in public spaces. } \\
\text { - Ministry of Health organizes and updates training for COVID-19 } \\
\text { sampling in hospitals. } \\
\text { Taiwan: } \\
\text { - government facilities are used for quarantine. } \\
\text { - soldiers are deployed to produce masks at local factories. } \\
\text { - } 60 \text { additional surgical mask machines are installed. The daily } \\
\text { output of masks is boosted to } 10 \text { million per day. } \\
\text { - a rationing system is announced for the purchase of masks. } \\
\text { - all travel from infected areas is banned. }\end{array}$ \\
\hline 20 & $\begin{array}{l}\text { Vietnam: } \\
\text { - Ministry of Health launches a virtual assistant about COVID-19 } \\
\text { - New Vietnam health application is publicized so that every citizen } \\
\text { can use it on their smartphone } \\
\text { - Emergency committees and training are put in place in most } \\
\text { affected regions } \\
\text { Taiwan: } \\
\text { - Tightens travel restrictions }\end{array}$ \\
\hline
\end{tabular}




\begin{tabular}{|c|c|}
\hline 25 & $\begin{array}{l}\text { Taiwan: } \\
\text { - NT } \$ 60 \text { billion (USD } 2 \text { billion) allocated for businesses affected by } \\
\text { the epidemic. } \\
\text { - Fines for violators of home isolation and quarantine regulations are } \\
\text { raised. } \\
\text { Vietnam: } \\
\text { - MoH implements a mandatory medical declaration for all } \\
\text { passengers entering from affected areas. }\end{array}$ \\
\hline 40 & $\begin{array}{l}\text { Both countries tighten travel restrictions and monitor recent } \\
\text { travelers closely. } \\
\text { Taiwan: } \\
\text { - } 6.45 \text { million surgical masks distributed to schools and after-school } \\
\text { institutions before the spring semester starts along with } 25.000 \\
\text { thermometers and } 84,000 \text { laters of alcohol-based sanitizers. } \\
\text { - Guidelines for suspension of classes due to confirmed COVID-19 } \\
\text { cases are published by the Ministry of Education } \\
\text { Vietnam: } \\
\text { - MoH issued recommendations for passengers on public transport } \\
\text { and vehicles using the developed apps. }\end{array}$ \\
\hline 45 & $\begin{array}{l}\text { Vietnam: } \\
\text { - MoH appoints a mobile team to support the treatment of COVID-19 } \\
\text { patients with severe symptoms in Central Tropical Hospital. } \\
\text { - Prime Minister shuts down unnecessary services }\end{array}$ \\
\hline 50 & $\begin{array}{l}\text { Vietnam: } \\
\text { - Isolation of the complete country to begin } \\
\text { - Prime Minister directed to support low-income workers with } \\
\quad \text { 42USD per month. }\end{array}$ \\
\hline
\end{tabular}

\section{Conclusions}

This manuscript highlights a broad range of early-stage policies, implemented by Taiwan and Vietnam, that formed an effective strategy to contain the spread of and build resilience against COVID-19. The two countries acted rapidly and followed similar interventions in the early stages of the epidemic including assessing the risks, organizing coordinated multi-actor responses, and informing the public about the potential risks of the crisis. After the first case was detected, both countries implemented effective systems of coordinated action across government sectors, closed schools, and took action on regulating the price of essential medical, and sanitary equipment. Despite acting similarly in the early stages of the epidemic, their strategies started differing as COVID-19 spread particularly in terms of travel restrictions and healthcare provision/training. We recommend that policies are dynamically adapted as further data related to 
COVID-19 becomes available, as a more accurate understanding allows more targeted policies. We hope that this article may serve as a source of information to develop better policies against COVID-19 worldwide, as well as future pandemic control protocols.

\section{References}

Anderson, R. M., Heesterbeek, H., Klinkenberg, D., and Hollingsworth, T. D. (2020). How will country-based mitigation measures influence the course of the COVID-19 epidemic? The Lancet 395, 931.

Armitage, R., and Nellums, L. B. (2020). COVID-19 and the consequences of isolating the elderly. Lancet Public Health. doi:10.1016/S2468-2667(20)30061-X.

Bastos, S. B., and Cajueiro, D. O. (2020). Modeling and forecasting the early evolution of the Covid-19 pandemic in Brazil. arXiv:2003.14288.

Keeling, M. J., Hollingsworth, T. D., and Read, J. M. (2020). The Efficacy of Contact Tracing for the Containment of the 2019 Novel Coronavirus (COVID-19). medRxiv, 2020.02.14.20023036.

La, V.-P., Pham, T.-H., Ho, M. T., Hoàng, N. M., Linh, N. P. K., Trang, V. T., et al. (2020). Policy response, social media and science journalism for the sustainability of the public health system amid COVID-19 outbreak: The Vietnam lessons. Sustainability 12, 2931.

Legido-Quigley, H., Asgari, N., Teo, Y. Y., Leung, G. M., Oshitani, H., Fukuda, K., et al. (2020). Are high-performing health systems resilient against the COVID-19 epidemic? The Lancet 395, 848.

Ohara, H. (2004). Experience and Review of Sars Control in Vietnam and China. Tropical Medicine and Health 32, 235.

Squillante, L., Mello, I. F., Seridonio, A. C., and de Souza, M. (2020). Attacking the Covid-19 with the Ising-model and the Fermi-Dirac Distribution Function. arXiv:2003.71860.

Wang, C. J., Ng, C. Y., and Brook, R. H. (2020). Response to COVID-19 in Taiwan: Big Data Analytics, New Technology, and Proactive Testing. JAMA323, 1341.

Webpage A Available at: https://www.cdc.gov.tw/En [Accessed April 23, 2020].

Webpage

B Available

at:

https://www.arcgis.com/apps/opsdashboard/index.html\#/bda7594740fd40299423 467b48e9ecf6 [Accessed April 23, 2020].

Zou, L., Ruan, F., Huang, M., Liang, L., Huang, H., Hong, Z., et al. (2020). SARS-CoV-2 Viral Load in Upper Respiratory Specimens of Infected Patients. New England Journal of Medicine 382, 1177. 